\title{
The effect of fluoride on enamel and dentin formation in the uremic rat incisor
}

\author{
Donacian M. Lyaruu • Antonius L. J. J. Bronckers • \\ Fernando Santos • Robert Mathias • Pamela DenBesten
}

Received: 28 August 2007 /Revised: 28 March 2008 / Accepted: 4 May 2008 / Published online: 19 June 2008

(C) The Author(s) 2008

\begin{abstract}
Renal impairment in children is associated with tooth defects that include enamel pitting and hypoplasia. However, the specific effects of uremia on tooth formation are not known. In this study, we used rat mandibular incisors, which continuously erupt and contain all stages of tooth formation, to characterize the effects of uremia on tooth formation. We also tested the hypothesis that uremia aggravates the fluoride (F)-induced changes in developing teeth. Rats were subjected to a two-stage $5 / 6$ nephrectomy or sham operation and then exposed to 0 (control) or $50 \mathrm{ppm}$ $\mathrm{NaF}$ in drinking water for 14 days. The effects of these treatments on food intake, body growth rate, and biochemical serum parameters for renal function and calcium metabolism were monitored. Nephrectomy reduced food intake and weight gain. Intake of $\mathrm{F}$ by nephrectomized rats increased plasma $\mathrm{F}$ levels twofold and further decreased food intake and body weight gain. Uremia affected formation of
\end{abstract}

D. M. Lyaruu $(\bowtie) \cdot$ A. L. J. J. Bronckers

Department of Oral Cell Biology,

Academic Centre for Dentistry Amsterdam (ACTA),

Room D246, v.d. Boechorststraat 7,

1081 BT Amsterdam, The Netherlands

e-mail: DM.Lyaruu@vumc.nl

F. Santos

Department of Pediatrics and Anatomy,

Instituto Universitario de Oncologia del Principado de Asturias,

University of Oviedo and Hospital Central de Asturias,

Oviedo, Spain

\section{R. Mathias}

Nemours Children's Clinic,

Orlando, FL, USA

\section{P. DenBesten}

Department of Growth and Development, UCSF Dental School, San Francisco, CA, USA dentin and enamel and was more extensive than the effect of $\mathrm{F}$ alone. Uremia also significantly increased predentin width and induced deposition of large amounts of osteodentin-like matrix-containing cells in the pulp chamber. In enamel formation, the cells most sensitive to uremia were the transitional-stage ameloblasts. These data demonstrate that intake of $\mathrm{F}$ by rats with reduced renal function impairs $\mathrm{F}$ clearance from the plasma and aggravates the already negative effects of uremia on incisor tooth development.

Keywords Fluoride · Uremia · Fluorosis · Incisor · Rat

\section{Introduction}

Fluoride (F) ingestion is associated with hypoplastic enamel (in healthy patients) and in severe cases can present itself as a pitted enamel surface $[1,2]$. During tooth formation, renal insufficiency is also associated with defective tooth structure, and in particular, enamel hypoplasia [3-5]. In patients with renal insufficiency, the decreased ability to excrete $F$ leads to increased retention of this anion. Indeed, the serum levels of $\mathrm{F}$ are elevated in children [6] and adults [7] with impaired renal function. The similarities between the appearance of fluorosed enamel $[1,2]$ and the hypoplastic enamel defects of uremia when it occurs during tooth formation led us to hypothesize that defective tooth structures in children with uremia may partially result from elevated serum F levels.

In this study, we tested this hypothesis using a rat incisor. This tooth model continuously erupts and contains all stages of dentin and enamel formation in a single tooth (see Fig. 1 diagram). Control and nephrectomized (Nx) rats were given $50 \mathrm{ppm} \mathrm{NaF}$ in their drinking water. This amount of $\mathrm{F}$ results in serum levels similar to humans ingesting 2-5 ppm $\mathrm{F}$ in drinking water. We hypothesized 


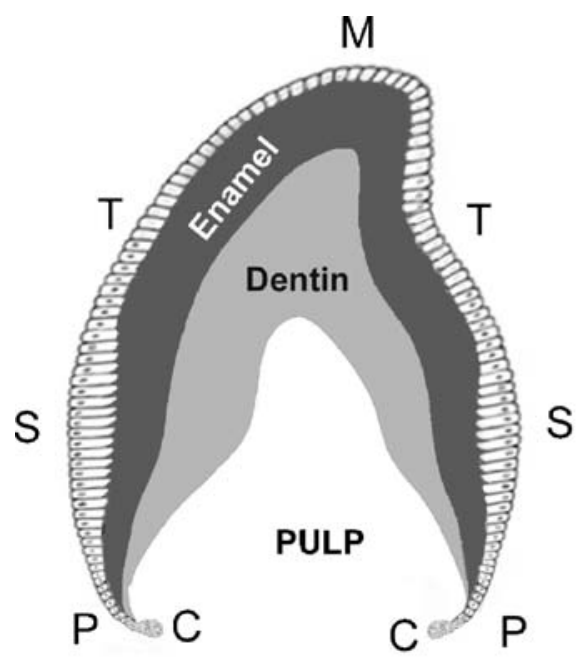

Fig. 1 Schematic comparison of the developing human incisor (left) and the continuously erupting rat incisor (right). The cervical loop region $(C)$ contains the progenitor cells that have the capacity to proliferate and develop into presecretory $(P)$ ameloblasts and eventually into secretory ameloblasts $(S)$ responsible for the deposition of provisionally mineralized protein-rich enamel. When almost the

that $\mathrm{F}$ supplementation under such conditions would result in increased F-induced pathology in the developing tooth during uremia, as the developing tooth organ will be exposed to higher levels of $\mathrm{F}$ from the circulatory system.

\section{Materials and methods}

\section{Experimental protocol}

Female Sprague-Dawley rats weighing $100 \pm 5 \mathrm{~g}$ underwent either a sham operation (S) or a two-stage $5 / 6 \mathrm{Nx}$, as previously described [8]. The $\mathrm{S}$ and $\mathrm{Nx}$ groups were further divided into two groups: one group was provided drinking water ad libitum supplemented with $50 \mathrm{ppm} \mathrm{NaF}$ from day 4 to day 18, and the second group (controls) were given deionized tap water. All animals were maintained on standard rat chow. The weight and food intake of the animals was determined at days 0,4 , and 18 . The animals were sacrificed by $\mathrm{CO}_{2}$ inhalation on day 18 . At the time of sacrifice, blood was obtained for determination of parameters for renal function, calcium metabolism, and serum $\mathrm{F}$ levels. The Committee on Animal Research of the University of Oviedo approved the procedures.

Biochemical analysis of serum for renal function and calcium metabolism

The serum samples of ten $\mathrm{S}$, ten $\mathrm{S}+\mathrm{F}$, ten $\mathrm{Nx}$, and nine nephrectomized plus $\mathrm{F}(\mathrm{Nx}+\mathrm{F})$ animals were analyzed for renal functioning. Blood urea nitrogen (BUN), serum creatinine $(\mathrm{Cr})$, and total calcium, phosphorus, and alkaline
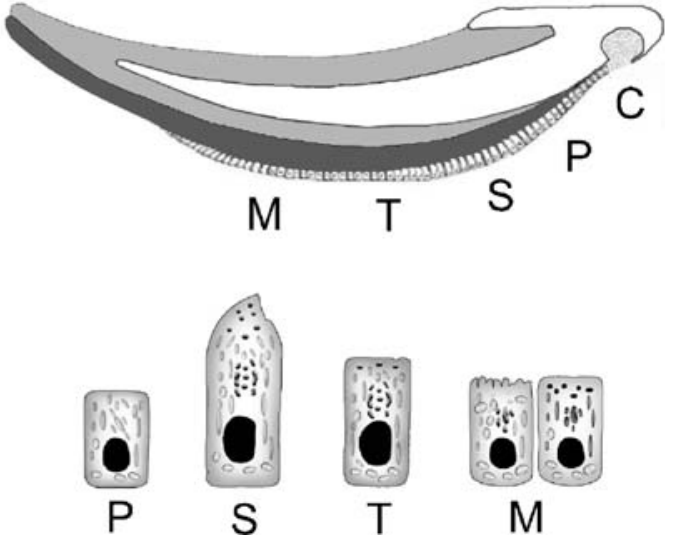

final enamel thickness has been deposited, the secretory ameloblasts transform through a short, so-called transitional, phase $(T)$ into maturation-stage ameloblasts $(M)$ responsible for enamel matrix resorption accompanied by massive mineralization of the enamel. Most of the maturation-stage ameloblasts $(M)$ die before the tooth erupts into the oral cavity

phosphatase concentrations were determined by an autoanalyzer (Analyzer Ektachem, Eastman Kodak, Rochester, NY). Plasma ionized calcium was determined by IRMA SL (Diametrics Medical, Inc., St. Paul, MN, USA). The F concentration in serum was measured directly by adding 200-400 $\mu$ l of sample to distilled water for a final concentration of $3 \mathrm{ml}$. The solution was mixed well, and $\mathrm{F}$ concentration was measured using an Orion $\mathrm{F}$ electrode [9].

Tissue preparation and histology

One hemimandible from each animal was immediately isolated after sacrifice, dissected free of adhering skin and muscle tissue, and then fixed in $4 \%$ formaldehyde in $0.1 \mathrm{M}$ phosphate buffer for $24 \mathrm{~h}$ at $4^{\circ} \mathrm{C}$. Tissues were demineralized in $10 \%$ ethylene diamine tetraacetic acid (EDTA) containing $0.8 \%$ formaldehyde, $\mathrm{pH} 7.4$, at room temperature on a shaker for 6 weeks. The demineralization solution was changed once a week. After demineralization, the tissues were washed overnight in $0.1 \mathrm{M}$ phosphate buffer, $\mathrm{pH} 7.4$, dehydrated in ascending alcohol series and routinely embedded in paraffin. Series of $7-\mu \mathrm{m}$-thick sections were prepared through the midsagittal plane and routinely stained with hematoxylineosin. Mandibular incisors from five $\mathrm{Nx}, \mathrm{S}$, and $\mathrm{S}+\mathrm{F}$ and six $\mathrm{Nx}+\mathrm{F}$, animals were examined histologically.

Measurements and statistics

The serum values of each group are given as mean \pm standard deviation (SD). Comparison among the four groups was performed by analysis of variance (ANOVA) using a significance level of $95 \%$, followed by the Newman-Keuls 
multiple range test. Measurements of predentin thickness were carried out on identical stages of development (midsecretory stage of amelogenesis) at a magnification of $200 x$ using a Leica DMRA microscope digitally coupled to a computer equipped with Leica Q-Win version 3 morphometry software (Leica Microsystems, Mannheim, Germany). Three sections were measured from each specimen, and the average was used as one measurement point. Five specimens from the $\mathrm{Nx}, \mathrm{S}$, and $\mathrm{S}+\mathrm{F}$ and six from $\mathrm{Nx}+\mathrm{F}$ groups were analyzed. The values were tested for significance with Students' $t$ test (unpaired) at $p<0.05$.

\section{Results}

Values for growth, renal function, fluoride, and calcium metabolism

Eighteen days after surgery, the levels of BUN and serum $\mathrm{Cr}$ were significantly higher in the $\mathrm{Nx}(52 \pm 16$ and $1.0 \pm$ $0.2 \mathrm{mg} / \mathrm{dl})$ and $\mathrm{Nx}+\mathrm{F}(49 \pm 12$ and $1.0 \pm 0.1 \mathrm{mg} / \mathrm{dl})$ animals than in the $\mathrm{S}(11 \pm 4$ and $0.5 \pm 0.0 \mathrm{mg} / \mathrm{dl})$ and $\mathrm{S}+\mathrm{F}(10 \pm 4$ and $0.5 \pm 0.0 \mathrm{mg} / \mathrm{dl}$ ) animals, respectively (Table 1 ).

$\mathrm{Nx}$ and $\mathrm{Nx}+\mathrm{F}$ animals were significantly growth-retarded compared with the $\mathrm{S}$ and $\mathrm{S}+\mathrm{F}$ animals (Table 1). Cumulative food intake was reduced in the $\mathrm{Nx}(183 \pm 34 \mathrm{~g})$ and $\mathrm{Nx}+\mathrm{F}$ $(149 \pm 20 \mathrm{~g})$ animals compared with $\mathrm{S}(250 \pm 18 \mathrm{~g})$ and $\mathrm{S}+\mathrm{F}$ $(282 \pm 24 \mathrm{~g})$ animals. Although F supplementation in uremic animals had no effect on renal function, their weight gain was less than that observed in the non-F-supplemented uremic animals. In contrast, $F$ supplementation had no effect on growth rate in $\mathrm{S}$ animals. Serum $\mathrm{F}$ levels were significantly increased in the $\mathrm{Nx}+\mathrm{F}$ animals (3.71

Table 1 Renal function, body growth rate, and cumulative food intake

\begin{tabular}{|c|c|c|c|c|}
\hline Parameter & Sham & $\begin{array}{l}\text { Sham + } \\
\text { fluoride }\end{array}$ & Nephrectomy & $\begin{array}{l}\text { Nephrectomy + } \\
\text { fluoride }\end{array}$ \\
\hline Number & 10 & 10 & 10 & 9 \\
\hline $\begin{array}{l}\text { Blood urea } \\
\text { nitrogen } \\
(\mathrm{mg} / \mathrm{dl})\end{array}$ & $11 \pm 4$ & $10 \pm 4$ & $52 \pm 16^{\mathrm{b}, \mathrm{c}}$ & $49 \pm 12^{\mathrm{b}, \mathrm{c}}$ \\
\hline $\begin{array}{l}\text { Serum } \\
\text { creatinine } \\
(\mathrm{mg} / \mathrm{dl})\end{array}$ & $0.5 \pm 0.0$ & $0.5 \pm 0.0$ & $1.0 \pm 0.2^{\mathrm{b}, \mathrm{c}}$ & $1.0 \pm 0.1^{\mathrm{b}, \mathrm{c}}$ \\
\hline Weight gain ${ }^{\mathrm{a}}(\mathrm{g})$ & $52 \pm 8$ & $64 \pm 13$ & $21 \pm 10^{\mathrm{b}, \mathrm{c}}$ & $10 \pm 9^{\mathrm{b}, \mathrm{c}, \mathrm{d}}$ \\
\hline Food intake $^{\mathrm{a}}(\mathrm{g})$ & $250 \pm 18$ & $282 \pm 24$ & $183 \pm 34^{\mathrm{b}, \mathrm{c}}$ & $149 \pm 20^{\mathrm{b}, \mathrm{c}, \mathrm{d}}$ \\
\hline
\end{tabular}

Values are mean \pm standard deviation

${ }^{a}$ Measured between days 4 and 18 of protocol

b Significantly different from sham

c Significantly different from sham+fluoride

d Significantly different from nephrectomy
Table 2 Serum parameters for fluoride (F) and calcium metabolism at the time of sacrifice

\begin{tabular}{|c|c|c|c|c|}
\hline Parameter & Sham & $\begin{array}{l}\text { Sham + } \\
\text { F }\end{array}$ & Nephrectomy & $\begin{array}{l}\text { Nephrectomy }+ \\
\text { F }\end{array}$ \\
\hline Number & 10 & 10 & 10 & 9 \\
\hline $\begin{array}{l}\text { Fluoride } \\
\qquad(\mu \mathrm{M})\end{array}$ & $0.79 \pm 0.31$ & $1.72 \pm 1.01$ & $1.08 \pm 0.31$ & $3.71 \pm 1.47^{\mathrm{a}, \mathrm{b}, \mathrm{c}}$ \\
\hline $\begin{array}{l}\text { Ionized calcium } \\
(\mathrm{mmol} / \mathrm{l})\end{array}$ & $1.07 \pm 0.31$ & $1.23 \pm 0.27$ & $0.93 \pm 0.34$ & $1.22 \pm 0.15^{\mathrm{c}}$ \\
\hline $\begin{array}{l}\text { Total calcium } \\
(\mathrm{mg} / \mathrm{dl})\end{array}$ & $9.0 \pm 1.0$ & $\begin{array}{c}11.6 \pm \\
1.2^{\mathrm{a}, \mathrm{c}}\end{array}$ & $9.8 \pm 0.6$ & $9.7 \pm 1.5^{\mathrm{b}}$ \\
\hline $\begin{array}{l}\text { Phosphorus } \\
(\mathrm{mg} / \mathrm{dl})\end{array}$ & $5.9 \pm 0.6$ & $7.5 \pm 1.8$ & $5.8 \pm 1.1$ & $9.4 \pm 2.6^{\mathrm{b}, \mathrm{c}}$ \\
\hline $\begin{array}{l}\text { Alkaline } \\
\text { phosphatase } \\
\text { (IU/l) }\end{array}$ & $167 \pm 43$ & $223 \pm 54$ & $337 \pm 78^{\mathrm{a}, \mathrm{b}}$ & $315 \pm 60^{\mathrm{a}, \mathrm{b}}$ \\
\hline
\end{tabular}

Values are mean \pm standard deviation

a Significantly different from sham

b Significantly different from sham $+F$

c Significantly different from nephrectomy

$1.47 \mu \mathrm{M})$ compared with the $\mathrm{S}(0.79 \pm 0.31 \mu \mathrm{M}), \mathrm{S}+\mathrm{F}$ $(1.72 \pm 1.01 \mu \mathrm{M})$, and $\mathrm{Nx}(1.08 \pm 0.31 \mu \mathrm{M})$ groups (Table 2$)$.

Concentrations of ionized serum calcium tended to be higher in the two groups of animals supplemented with $\mathrm{F}$ than in the unsupplemented groups (Table 2). F supplementation resulted in higher serum phosphorus levels in the $\mathrm{S}+\mathrm{F}(7.5 \pm 1.8 \mathrm{mg} / \mathrm{dl})$ and $\mathrm{Nx}+\mathrm{F}(9.4 \pm 2.6 \mathrm{mg} / \mathrm{dl})$ animals than in the $\mathrm{S}$ and $\mathrm{Nx}$ groups. The serum alkaline phosphatase levels were significantly higher in the $\mathrm{Nx}$ and $\mathrm{Nx}+\mathrm{F}$ animals than in the $\mathrm{S}$ and $\mathrm{S}+\mathrm{F}$ animals.

\section{Histology}

For orientation purposes, Fig. 1 shows a schematic comparison of the continuously erupting rat incisor with the human incisor tooth. The whole development of the rat incisor takes 35 days to complete, whereas in humans, it can take from 3 years to more than 10 years to develop, depending upon the tooth type in question. The cervical loop region at the base of the tooth contains the progenitor cells that have the capacity to divide and generate functional ameloblasts (Fig. 1). The initial event at the cervical loop region is the formation of relatively short columnar preameloblasts that eventually differentiate into highly elongated secretory cells responsible for the deposition of provisionally mineralized enamel. After a relatively short transitional stage, when many of the cells die through apoptosis, the remaining ameloblasts shorten and transform into resorptive cells - the maturation-stage ameloblasts. At this stage, the enamel matrix proteins are removed from the enamel, accompanied by massive 
Fig. 2 Parasagittal photomontage from sham-operated fluoride-treated $(\mathrm{S}+\mathrm{F})(\mathbf{a})$ and nephrectomized fluoride-treated $(\mathrm{Nx}+\mathrm{F})(\mathbf{b})$ specimens. The pulp chamber $(D P)$ of the $\mathrm{S}+\mathrm{F}$ specimen appears normal (a), whereas the $\mathrm{Nx}+\mathrm{F}$ pulp chamber contains large amounts of osteodentin-like matrix (b, asterisks; see also Fig. 5b for details) and near the predentin layer (arrowheads; see also Fig. 5a for details). In addition, the cementum-related (root) dentin is discontinuous in the $\mathrm{Nx}+\mathrm{F}$ specimen (black arrows). B bone, $D$ dentin. (Bars $=$ $1000 \mu \mathrm{m})$
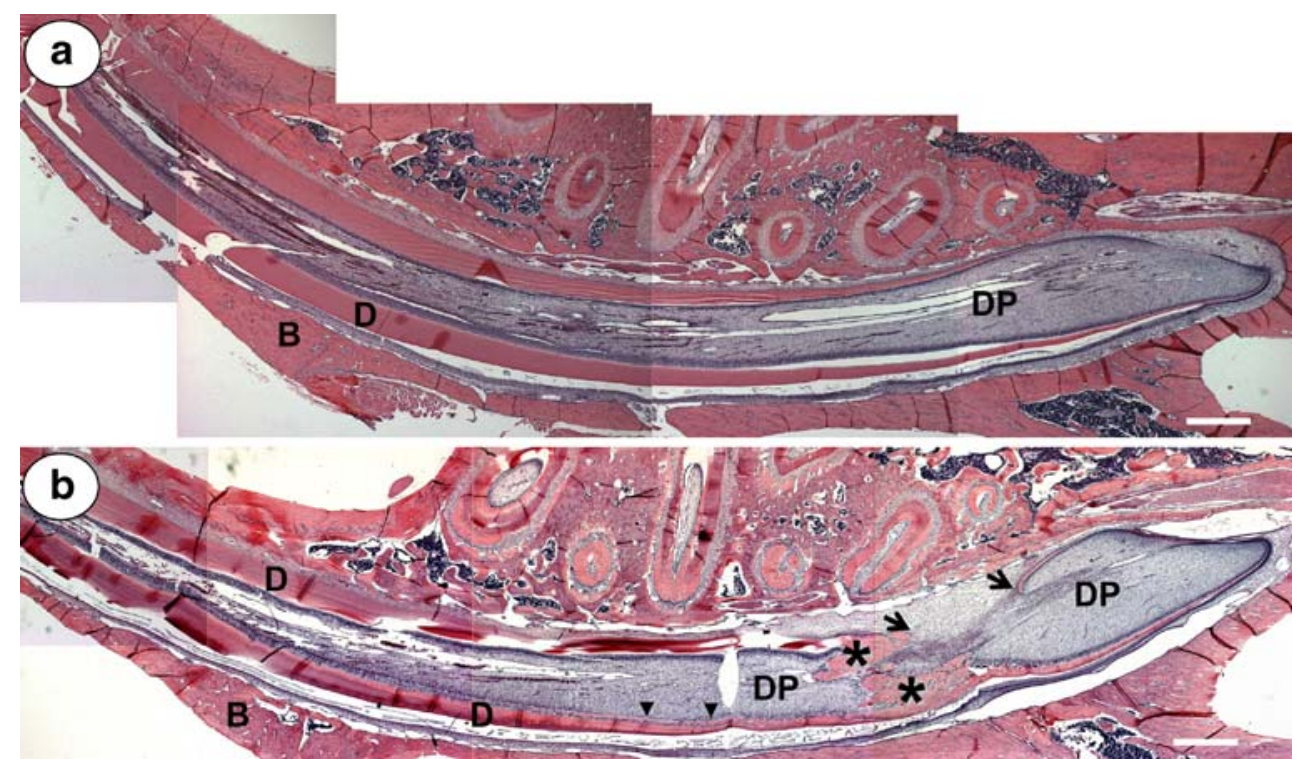

mineralization of the tissue. Most of the maturation-stage ameloblasts die just before tooth eruption.

Figure $2 \mathrm{a}, \mathrm{b}$ shows, respectively, parasagittal survey photo montages of $\mathrm{S}+\mathrm{F}$ and $\mathrm{Nx}+\mathrm{F}$ rat incisors. To determine the effect of $\mathrm{Nx}$ alone on incisor development, we compared incisors of the $\mathrm{S}$ group (Fig. 3a) with those of $\mathrm{Nx}$ animals (Fig. 3b). The most prominent effect seen in all uremic animals was widening of the predentin layer beginning with the earliest stages of dentinogenesis (Fig. 3b).

A second remarkable change after $\mathrm{Nx}$ was that the transitional-stage ameloblasts in the uremic incisors were always disorganized (Fig. 4a), a phenomenon not seen in the $\mathrm{S}$ animals. In some specimens, intact enamel (and also dentin) layers were absent under these cells (Fig. 4b). Secretory ameloblast or maturation ameloblasts were not visibly affected.

The third pathological change induced by uremia was the deposition of large amounts of osteodentin-like matrix in the dental pulp chamber in $\mathrm{Nx}$ rats roughly starting in the pulp region under the late secretory- to transitional-stage ameloblasts (Figs. 2b and 5b, asterisks). The amount of unmineralized matrix in the pulp chamber increased in the incisal direction, and in many cases, even filled the pulp chamber completely (Figs. 2b and 5b, asterisks). The staining characteristics of this matrix with hematoxylin-eosin suggested that this matrix was not mineralized prior to decalcification of these samples in preparation for histological processing [10]. This matrix often contained embedded cells (Fig. 5a, arrows), and the odontoblasts lining these matrix aggregates often appeared disorganized (Fig. 5a).

Effect of fluoride on the incisor after nephrectomy

$\mathrm{S}$ rats exposed to $\mathrm{F}$ in three out of the five specimens showed changes in the transitional ameloblasts. These cells were disorganized and had formed underlying cysts. No obvious changes were noted in the secretory or maturationstage ameloblasts, dental pulp, or odontoblasts (Fig 2b). Predentin thickness in S rats was not visibly affected by $\mathrm{F}$. The F-induced changes in the incisors of the $\mathrm{S}$ rats were in general mild compared with those changes seen in the $\mathrm{Nx}$ rats. Subameloblastic cystic lesions were not observed in the $\mathrm{S}$ or $\mathrm{Nx}$ animals.
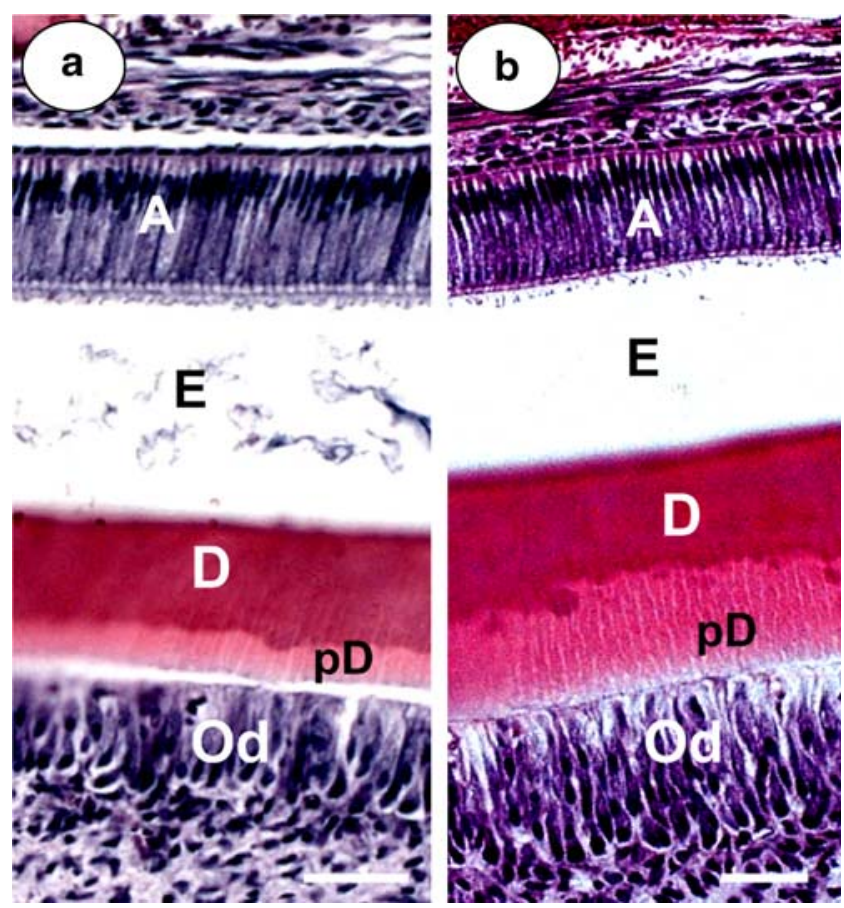

Fig. 3 Micrograph of the secretory stage of enamel and dentin in sham-operated (S) (a) and nephrectomized (Nx) (b) specimen. The predentin layer $(p D)$ in the Nx specimen is clearly wider than that of the $\mathrm{S}$ specimen. The presecretory (not shown) and secretory ameloblasts $(A)$ as and odontoblasts $(O d)$ appear normal. $D$ dentin, $E$ enamel space. $($ Bars $=50 \mu \mathrm{m})$ 

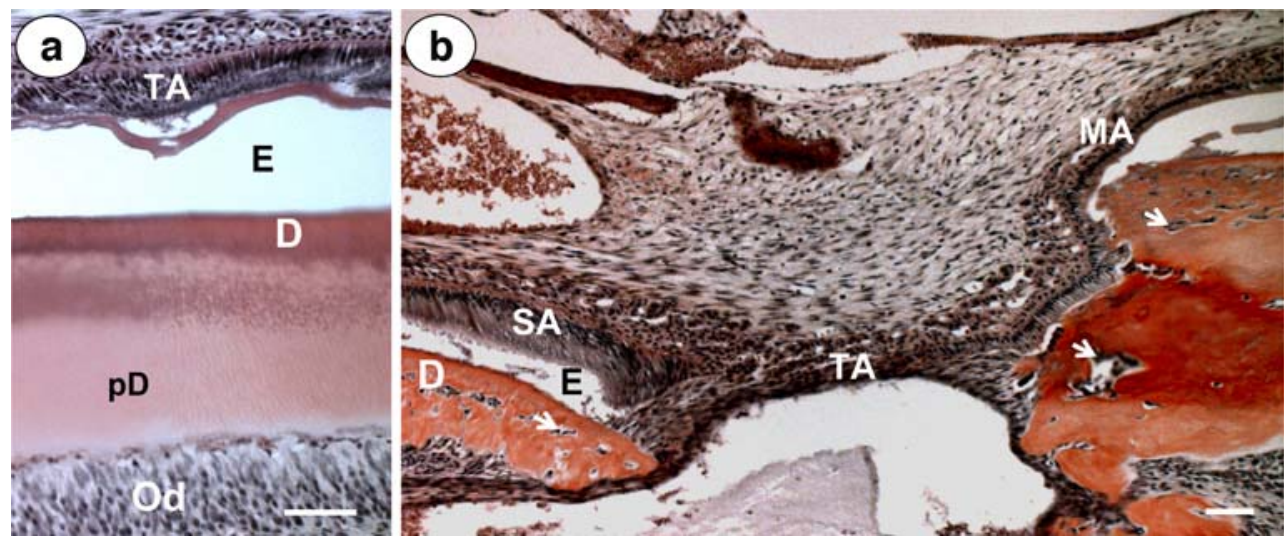

Fig. 4 Micrographs taken from two different nephrectomized $(\mathrm{Nx})$ specimens demonstrate how nephrectomy can differently affect transitional-stage ameloblasts $(T A)$. In a, TA, although affected, were presumably able to maintain intact enamel $(E)$ and dentin $(D)$ layers,

whereas those shown in $\mathbf{b}$ were not (gap area: black arrow). White arrows in $\mathbf{b}$ indicate cells embedded in matrix. Od odontoblasts, $p d$ predentin, $S A$ secretory ameloblasts. (Bars $=50 \mu \mathrm{m})$

Administration of $\mathrm{F}$ to the uremic animals led to more severe development disturbances of the incisor, and in particular, on the transitional-stage ameloblasts, which were more disorganized compared with Nx animals (Fig. 4a). In some cases, the enamel or dentin layers were locally completely absent at these locations (Fig. 4b). F also induced the formation of more extensive cyst-like lesions under the transitional ameloblasts (Fig. 5a) found in all specimens examined. Note that a gap was observed in the root dentin in some (but not all) $\mathrm{F}+\mathrm{Nx}$ animals (Fig. 5b, black double arrow). This phenomenon was also observed in some of the uremic animals not exposed to high-dose $\mathrm{F}$, indicating that this is most likely not a specific F-related event.

As was the case with the $\mathrm{Nx}$ animals exposed to deionized water, the increase in width of the predentin was also observed in the $\mathrm{Nx}$ animals exposed to $\mathrm{F}$ in the drinking water. Measurements of predentin thickness showed a significant increase in width in the $\mathrm{Nx}$ animals compared with either the $\mathrm{S}$

and S+F animals (Fig. 6), confirming that uremia with or without $\mathrm{F}$ in the drinking water widened the predentin layer compared with control animals.

\section{Discussion}

There are a series of retrospective clinical studies (in children or adults) with chronic renal failure, end-stage renal disease, or following kidney transplantation that have associated poor renal function with enamel developmental defects in primary (mainly canines [5]) and permanent dentition [4, 11, 12]. Moreover, the severity of the renal-failure-induced pathology in dentition is correlated with age at disease onset. Most teeth are affected if renal insufficiency occurs during the first 4 years of childhood [11]. The enamel defects described in these studies include demarcated and diffuse enamel opacities and the more serious enamel hypoplasia (pits). To date,

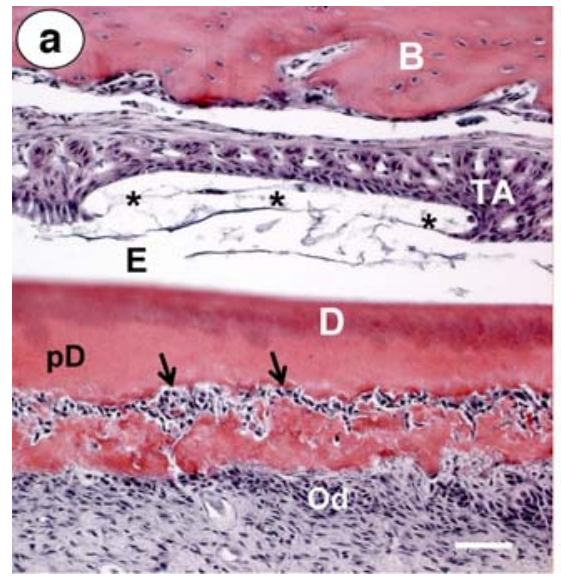

Fig. 5 a Cyst-like lesion (asterisks) seen under the transitional-stage ameloblasts $(T A)$ in a nephrectomized fluoride-treated $(N x+F)$ specimen. Such lesions were not observed in the sham-operated fluoridetreated $(S+F)$ or in sham-operated (S) control specimens. Also, unmineralized matrix-containing cells embedded in them can be seen in the vicinity of the predentin $(p D)$ (arrows). The odontoblasts $(O d)$

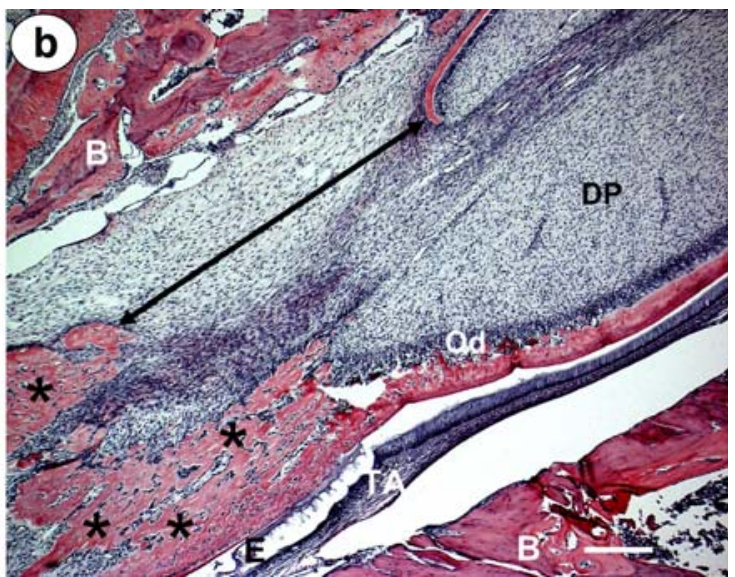

have lost their characteristic columnar arrangement. b Detail of Fig. 1b shows a gap in the cementum-related dentin (black arrow) opposite the affected TA. Large amounts of matrix (asterisks) almost completely obliterate the dental pulp $(D P)$ chamber. $B$ bone, $D$ dentin, $E$ enamel space. $[$ Bars $=100 \mu \mathrm{m}(\mathbf{a})$ and $250 \mu \mathrm{m}(\mathbf{b})]$ 


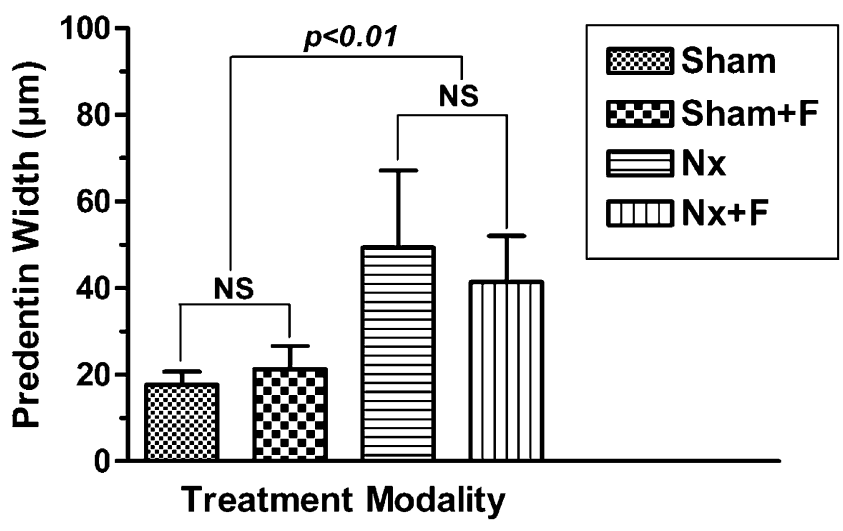

Fig. 6 Predentin thickness: the predentin layer is significantly wider in the nephrectomized animals (with or without fluoride treatment) than in the either the sham-operated or sham-operated fluoride-treated animals, indicating that the widening of the predentin is not a fluoriderelated event

no experimental data have been reported on the effects of $\mathrm{Nx}$ alone on tooth development.

In our study, we used a subtotal Nx model to investigate the effects of uremia on serum $\mathrm{F}$ levels and tooth histology. We also demonstrated that $\mathrm{F}$ supplementation to both $\mathrm{S}$ and $\mathrm{Nx}$ animals was associated with elevated serum $\mathrm{F}$ levels. The enhanced serum $\mathrm{F}$ level in Nx rats is likely the result of the reduced $\mathrm{F}$ clearance from the circulatory system by the kidneys. However, reduced incorporation of $\mathrm{F}$ into the mineralizing tissues in the uremic rats cannot be ruled out.

This is the first study to demonstrate that the primary effect of renal insufficiency on tooth formation was a disruption of dentinogenesis. This effect was developmental-stage dependent. In fully differentiated odontoblasts (incisal portion of the incisor), $\mathrm{Nx}$ induced a delay of transformation of predentin into dentin, causing a widening of the predentin layer. Similar changes have been found in human teeth from patients with renal transplants $[13,14]$.

Cells situated in the more apical areas of the incisor that were undifferentiated or differentiating at onset of $\mathrm{Nx}$ were extremely vulnerable and formed, instead, of predentin, a bone-like matrix that sometimes filled the whole pulp chamber. Such changes in the pulp may be related to the high incidence of pulp calcifications found in teeth by radiography in patients with renal transplants or undergoing dialysis [4, 15]. Similar histological changes have been reported in incisors from animals injected with anticancer drugs such as adriamycin [16]. To date, the factors responsible for such changes are unknown.

Widening of predentin has also been reported in rickets (vitamin D deficiency) and during disturbance of calcium and phosphate metabolism [17, 18]. Disturbances in calcium and phosphate metabolism are commonly seen in patients with long-standing renal disease [19, 20]. In our study, ionized calcium levels were lower and serum alkaline phosphatase levels were higher in Nx animals compared with controls.
Subtotal Nx also appeared to affect ameloblasts. The transitional-stage ameloblasts appear to be particularly sensitive to both the effects of uremia and F. However, uremia alone had more serious effects than the effect of $50 \mathrm{ppm} \mathrm{NaF}$ in drinking water in control animals. In the latter group, $50 \mathrm{ppm} \mathrm{NaF}$ in drinking water resulted in the formation of cysts under transitional ameloblasts, which was not seen in uremic animals without $\mathrm{F}$ exposure. In a previous study, we proposed that such F-induced cyst formation in transitional-stage ameloblasts is associated with local enamel hypoplasia seen as pits at the enamel surface of erupted teeth [21].

The mean F level in S rats was $0.79 \mu \mathrm{M}$, which is in the range of normal serum $F$ levels found in humans [22, 23]. Serum levels in young children are somewhat lower, most likely due to increased uptake into the rapidly forming bone $[22,24]$. Serum $\mathrm{F}$ levels in $\mathrm{Nx}$ rats exposed to tap water (deionized water) were higher compared with $\mathrm{S}$ rats, although this difference was not statistically significant.

On the other hand, when $50 \mathrm{ppm} \mathrm{NaF}$ was added to the drinking water, serum $\mathrm{F}$ levels in $\mathrm{S}$ animals rose to $1.72 \mu \mathrm{M}$, similar to humans ingesting $2-3 \mathrm{ppm} F$ in their drinking water. At these serum $\mathrm{F}$ levels, cysts formed, and the effects were more severe in uremic animals with even higher serum $\mathrm{F}$ levels following $\mathrm{F}$ supplementation. This data supports the hypothesis that the effects of $F$ on developing enamel would potentially be more severe in children with renal insufficiency than in children with normal renal function. Moreover, these data also suggest that other factors, in addition to elevated serum F levels, may play a role in the disturbances seen in developing teeth in uremic animals.

In summary, these studies show that tooth development is disturbed under uremic conditions. The effects of uremia are primarily in the dentin but also occur in enamel, resulting in hypoplasia and pitting of the enamel surface. The crown portion of human central incisors (the most aesthetically visible teeth) forms up to approximately 4 years of age, with the second permanent molars forming by about 8 years of age. Therefore, children who present with renal insufficiency before the age of 8 years are at risk for tooth defects. These effects will be more severe in the presence of $\mathrm{F}$, and ingestion of $\mathrm{F}$ by young children with renal failure (i.e. F supplements or swallowing F-containing toothpaste) is contraindicated, as suggested previously [4]. Further studies to determine the stage-specific effects of uremia and $\mathrm{F}$ on tooth formation may result in a better understanding of the overall effects of uremia on mineralized tissues such as dentin, enamel, and bone.

Acknowledgements This work was supported by NIH grant DE13508-06 (PDB, DL, and AB). The authors thank Paulien Holzmann, Deptartment of Oral Cell Biology, ACTA, and Justine 
Dobeck, Forsyth Dental Institute, Boston, MA, USA, for their technical assistance in tissue preparation and histology, and Joseph Mendoza for preparation of the illustration depicted in Fig. 1.

Open Access This article is distributed under the terms of the Creative Commons Attribution Noncommercial License which permits any noncommercial use, distribution, and reproduction in any medium, provided the original author(s) and source are credited.

\section{References}

1. Fejerskov O, Thylstrup A, Larsen MJ (1977) Clinical and structural features and possible pathogenic mechanisms of dental fluorosis. Scand J Dent Res 85:510-534

2. Denbesten PK (1999) Biological mechanisms of dental fluorosis relevant to the use of fluoride supplements. Community Dent Oral Epidemiol 27:41-47

3. Farge P, Ranchin B, Cochat P (2006) Four-year follow-up of oral health surveillance in renal transplant children. Pediatr Nephrol 21:851-855

4. Lucas VS, Roberts GJ (2005) Oro-dental health in children with chronic renal failure and after renal transplantation: a clinical review. Pediatr Nephrol 20:1388-1394

5. Koch MJ, Buhrer R, Pioch T, Scharer K (1999) Enamel hypoplasia of primary teeth in chronic renal failure. Pediatr Nephrol 13:68-72

6. Spak CJ, Berg U, Ekstrand J (1985) Renal clearance of fluoride in children and adolescents. Pediatrics 75:575-579

7. Schiffl HH, Binswanger U (1980) Human urinary fluoride excretion as influenced by renal functional impairment. Nephron 26:69-72

8. Mathias RS, Nguyen HT, Zhang MY, Portale AA (1998) Reduced expression of the renal calcium-sensing receptor in rats with experimental chronic renal insufficiency. J Am Soc Nephrol 9:2067-2074

9. Mathias RS, Amin U, Mathews CH, Denbesten P (2000) Increased fluoride content in the femur growth plate and cortical bone of uremic rats. Pediatr Nephrol 14:935-939

10. Beertsen W, Niehof A, Everts V (1985) Effects of 1hydroxyethylidene-1, 1-bisphosphonate (HEBP) on the formation of dentin and the periodontal attachment apparatus in the mouse. Am J Anat 174:83-103
11. Nunn JH, Sharp J, Lambert HJ, Plant ND, Coulthard MG (2000) Oral health in children with renal disease. Pediatr Nephrol 14:997-1001

12. Al Nowaiser A, Roberts GJ, Trompeter RS, Wilson M, Lucas VS (2003) Oral health in children with chronic renal failure. Pediatr Nephrol 18:39-45

13. Wysocki GP, Daley TD, Ulan RA (1983) Predentin changes in patients with chronic renal failure. Oral Surg Oral Med Oral Pathol 56:167-173

14. Nasstrom K, Moller B, Petersson A (1993) Effect on human teeth of renal transplantation: a postmortem study. Scand J Dent Res 101:202-209

15. Scutellari PN, Orzincolo C, Bedani PL, Romano C (1996) [Radiographic manifestations in teeth and jaws in chronic kidney insufficiency]. Radiol Med (Torino) 92:415-420

16. Karim AC (1985) The initiation of osteodentin formation in the rat incisor after adriamycin administration. Anat Rec 213: 377-384

17. Murayama T, Iwatsubo R, Akiyama S, Amano A, Morisaki I (2000) Familial hypophosphatemic vitamin D-resistant rickets: dental findings and histologic study of teeth. Oral Surg Oral Med Oral Pathol Oral Radiol Endod 90:310-316

18. Abe K, Ooshima T, Lily TS, Yasufuku Y, Sobue S (1988) Structural deformities of deciduous teeth in patients with hypophosphatemic vitamin D-resistant rickets. Oral Surg Oral Med Oral Pathol 65:191-198

19. Leonard MB, Zemel BS (2002) Current concepts in pediatric bone disease. Pediatr Clin North Am 49:143-173

20. Salusky IB (1995) Bone and mineral metabolism in childhood end-stage renal disease. Pediatr Clin North Am 42:1531-1550

21. Lyaruu DM, Bervoets TJ, Bronckers AL (2006) Short exposure to high levels of fluoride induces stage-dependent structural changes in ameloblasts and enamel mineralization. Eur J Oral Sci 114 (Suppl 1):111-115

22. Torra M, Rodamilans M, Corbella J (1998) Serum and urine ionic fluoride: normal range in a nonexposed population. Biol Trace Elem Res 63:67-71

23. Husdan H, Vogl R, Oreopoulos D, Gryfe C, Rapoport A (1976) Serum ionic fluoride: normal range and relationship to age and sex. Clin Chem 22:1884-1888

24. Hossny E, Reda S, Marzouk S, Diab D, Fahmy H (2003) Serum fluoride levels in a group of Egyptian infants and children from Cairo city. Arch Environ Health 58:306-315 